\title{
Sensory Analysis of Chocolate Milk for College Students
}

\section{Chizoti TS ${ }^{1}$, Cruz MF${ }^{1}$, Benassi MT², Brugnaro $\mathrm{C}^{1}$, de Medeiros SDS ${ }^{1}$, Bordi Jr $\mathrm{PL}^{3}$ and Verruma-Bernardi $\mathrm{MR}^{{ }^{1}}$}

${ }^{1}$ Center for Agrarian Sciences, Federal University of São Carlos, Rodovia Anhanguera, SP, Brazil

${ }^{2}$ Center for Agrarian Sciences, State University of Londrina, Rodovia Celso Garcia Cid, Londrina, PR, Brazil

${ }^{3}$ Center for Food Innovation, School of Hospitality Management, Pennsylvania State University, University Park, PA, USA

*Corresponding author: Verruma-Bernardi MR, Center for Agrarian Sciences, Federal University of São Carlos, Rodovia Anhanguera, Km 174, 13600-970, Araras, SP, Brazil, Tel: 5511 1635432615, E-mail: verruma@ufscar.br

Citation: Chizoti TS, Cruz MF, Benassi MT, Brugnaro C, de Medeiros SDS, et al. (2018) Sensory Analysis of Chocolate Milk for College Students. J Obes Overweig 4(1): 107. doi: 10.15744/2455-7633.4.107

Received Date: November 17, 2017 Accepted Date: May 28, 2018 Published Date: May 30, 2018

\begin{abstract}
The study explores the impact of varying levels of added sugar on the sensory characteristics of chocolate milk. Chocolate milk formulations were studied with five levels of added sugar (g): 0 (A), 7 (B), 14 (C), 21 (D) and $28 \mathrm{~g}$ (E) in 237 mL of chocolate milk. For Ranking Descriptive Analysis (RDA), the panel was composed of 15 assessors. The acceptance was evaluated by 190 assessors. Sample discrimination was correlated with sweetness flavor, texture, sweet aroma, chocolate flavor and creamy appearance. It was observed that attributes like sweet aroma, sweetness and texture showed a significant difference among the samples. Formulations $\mathrm{C}, \mathrm{D}$ and $\mathrm{E}$ got higher grades 4 and attributes for milk $\mathrm{A}$ and $\mathrm{B}$ were less acceptable mainly regarding flavor and texture. The data showed that the samples containing the highest concentrations of added sugar were more preferred than those with lower sugar levels.
\end{abstract}

Keywords: Sensory Analysis; Sucrose; Consumer

\section{Introduction}

Milk and dairy products are important components of many diets based on the nutrients they contain, including calcium and vitamin D [1]. Eduardo and Lannes [2] reported that chocolate is eaten in many parts of the world by people of all ages and social classes, in many forms, ranging from powders to flavored milk. Murphy et al. [3] reported the positive effect of flavored or plain milk consumption on nutrient intake. Chocolate milk has a higher calorific value than the natural product. For the added calories not to discourage milk consumption and all its benefits, Li et al. [4] advised reducing the sugar content of chocolate milk as much as possible while still maintaining acceptability among consumers.

Ranking tests are usually employed to compare multiple samples with different intensities of a given attribute [5]. Some studies have explored the use of a ranking procedure with a descriptive purpose [6,7] and in such cases, it is recommended to involve at least 15 judges [8]. Richter et al. [7] proposed the method Ranking Descriptive Analysis and reported that it allowed the discrimination of the samples studied (chocolate pudding) with similar efficiency to the traditional descriptive ones.

According to Carnelocce et al. [9], the Ranking Descriptive Analysis offers the standardization of scale extremes and the selection of judges and possible training repetition. The authors also highlighted that RDA reduce the time and cost of a product in the description, to the extent that requires fewer and smaller amounts of sessions for each sample.

The acceptance tests are used to evaluate how much consumers like or dislike the product [10], with important complementary information to the product description to assess whether a sensory characteristic impacts consumer acceptance.

The objective of this research was to study the sensory characteristics of chocolate milk formulations with varying levels of sugar to ascertain how sugar affects the preference of chocolate milk.

\section{Materials and Methods}

\section{Sample preparation and conditions of sensory tests}

Chocolate milk formulations were prepared using sterilized skimmed milk and cocoa powder, $2 \mathrm{~g}$ per $100 \mathrm{~mL}$ of milk. Five concentrations of added sugar were studied: $\mathrm{A}=0, \mathrm{~B}=7, \mathrm{C}=14, \mathrm{D}=21$ and $\mathrm{E}=28 \mathrm{~g}$ in $237 \mathrm{~mL}$ of chocolate milk. The samples were served in transparent cups $(50 \mathrm{~mL})$ at $7{ }^{\circ} \mathrm{C}$ and coded with random-three digit numbers and at natural lighting. The tests were 
performed in the Sensory Analysis Laboratory, Federal University of São Carlos. The project was approved by the Ethics in Human Research (number 0143.0.268.000-09).

\section{Ranking Descriptive Analysis (RDA)}

For Ranking Descriptive Analysis (RDA) [7] a panel of 15 judges was used. Initially, a survey of attributes was conducted using the repertory method [11]. Each judges described similarities and differences between the samples regarding to appearance, aroma, flavor and texture.

A qualitative inquiry was then undertaken to determine the most cited descriptive terms and develop a list of consensus descriptors, as well as a glossary. It was defined that attributes cited by more than $50 \%$ by the judges. Sample evaluation by RDA was completed in one session. The samples were simultaneously presented and each assessor ordered samples in ascending order of intensity for each of the attributes.

\section{Acceptance test}

Sample acceptance was evaluated by a panel of 190 students between ages 18 and 25 . The samples were evaluated for appearance, aroma, flavor, texture and overall acceptance using a seven-point scale. The presentation order of the samples was monadic and sequential, following a balanced complete blocks design [12].

\section{Analysis of the results}

Ranking results were evaluated by the Friedman test [13] at a 5\% significance level. Acceptance data was analyzed by analysis of variance, considering sample and judge as sources of variation, followed by Tukey's test at a 5\% significance level and internal preference maps were generated using the R software system [14].

\section{Results and Discussion}

\section{Ranking Descriptive Analysis}

The following attributes were selected (number of times cited by the 15 judges): brown color (10), creamy appearance (8), chocolate flavor (8), sweet aroma (15), chocolate taste (8), sweetness (15) and texture (14). Studies described by Pflanzer et al. [15] noted attributes such as brown color, chocolate flavor, sweetness and texture.

\begin{tabular}{|c|c|c|c|c|c|c|c|c|c|c|c|c|c|c|}
\hline $\begin{array}{c}\text { Chocolate } \\
\text { milk }\end{array}$ & \multicolumn{2}{|c|}{ Brown Color } & \multicolumn{2}{c|}{$\begin{array}{c}\text { Creamy Ap- } \\
\text { pearance }\end{array}$} & \multicolumn{2}{c|}{$\begin{array}{c}\text { Chocolate } \\
\text { Flavor }\end{array}$} & \multicolumn{2}{|c|}{ Sweet Aroma } & \multicolumn{2}{c|}{$\begin{array}{c}\text { Chocolate } \\
\text { Taste }\end{array}$} & \multicolumn{2}{|c|}{ Sweetness } & \multicolumn{2}{c|}{ Texture } \\
\hline A & 45 & $\mathrm{a}$ & 40 & $\mathrm{a}$ & 41 & $\mathrm{a}$ & 28 & $\mathrm{~b}$ & 33 & $\mathrm{a}$ & 17 & $\mathrm{~d}$ & 29 & $\mathrm{~b}$ \\
\hline B & 46 & $\mathrm{a}$ & 42 & $\mathrm{a}$ & 43 & $\mathrm{a}$ & 39 & $\mathrm{ab}$ & 42 & $\mathrm{a}$ & 33 & $\mathrm{~cd}$ & 39 & $\mathrm{ab}$ \\
\hline C & 43 & $\mathrm{a}$ & 46 & $\mathrm{a}$ & 50 & $\mathrm{a}$ & 47 & $\mathrm{ab}$ & 38 & $\mathrm{a}$ & 44 & $\mathrm{bc}$ & 45 & $\mathrm{ab}$ \\
\hline D & 45 & $\mathrm{a}$ & 44 & $\mathrm{a}$ & 41 & $\mathrm{a}$ & 50 & $\mathrm{ab}$ & 55 & $\mathrm{a}$ & 61 & $\mathrm{ab}$ & 55 & $\mathrm{a}$ \\
\hline E & 46 & $\mathrm{a}$ & 53 & $\mathrm{a}$ & 51 & $\mathrm{a}$ & 61 & $\mathrm{a}$ & 57 & $\mathrm{a}$ & 70 & $\mathrm{a}$ & 57 & $\mathrm{a}$ \\
\hline
\end{tabular}

${ }^{*}$ Sums followed by the same letters did not differ significantly from each other by the critical values of Newell and MacFarlane (1987) at a $5 \%$ significance level (15 judges; critical value: 24 ). $\mathrm{A}=0 \mathrm{~g}, \mathrm{~B}=7 \mathrm{~g}, \mathrm{C}=14 \mathrm{~g}, \mathrm{D}=21 \mathrm{~g}$ and $\mathrm{E}=28 \mathrm{~g}$ of added sugar in $237 \mathrm{~mL}$ of chocolate milk Table 1: Characterization of the samples by RDA

It was found that the attributes sweet aroma, sweetness, chocolate taste and texture showed significant difference among the samples (Table 1); therefore, the change in the proportion of sugar did not result in differences in the perception of brown color, creamy appearance and chocolate taste. For the attributes sweet aroma and chocolate flavor, samples A and E showed a significant difference, but no difference was detected among the others.

Evaluating attribute by attribute, it was found that the samples without sugar (A) and at the 12\% level (E) differ significantly in relation to flavor and sweet taste, chocolate flavor and texture. The discriminating attribute allowed texture for sample without sugar $21 \mathrm{~g}$ (D), but no difference in texture was observed with increasing addition of sugar until $28 \mathrm{~g}$. Sweet taste showed the greatest difference, with a significant discrimination between the sample without sugar (A) and the samples above, with $14 \mathrm{~g}(\mathrm{C}$, $\mathrm{D}$ and $\mathrm{E})$.

\section{Acceptance of milk with chocolate}

Table 2 shows there was a variation in the acceptance of all samples regarding all attributes. In Figure 1, the two principal components account for $64.35 \%$ of the variation in the acceptance of the chocolate samples compared to color. PC1 component, which explains the greatest variation of acceptability of the color attribute (37.93\%), spatially separates the samples on the left of its axis (less preferred samples for color) and on the right of its axis (most preferred samples for color) (Figure 1). 


\begin{tabular}{|c|c|c|c|c|c|c|c|c|c|c|}
\hline Chocolate milk $^{*}$ & \multicolumn{2}{|r|}{ Color } & \multicolumn{2}{|c|}{ Aroma } & \multicolumn{2}{|c|}{ Flavor } & \multicolumn{2}{|c|}{ Texture } & \multicolumn{2}{c|}{ Global acceptance } \\
\hline A & 4.5 & b & 4.2 & c & 2.0 & d & 3.4 & d & 2.6 & d \\
\hline B & 4.8 & a & 4.5 & b & 3.1 & c & 3.9 & c & 3.6 & $\mathrm{c}$ \\
\hline C & 5.0 & a & 4.8 & a & 4.4 & b & 4.5 & b & 4.5 & $\mathrm{~b}$ \\
\hline D & 5.1 & a & 5.0 & a & 5.0 & a & 4.8 & a & 5.0 & a \\
\hline E & 5.2 & a & 4.8 & a & 5.1 & a & 4.9 & a & 5.0 & a \\
\hline
\end{tabular}

$\mathrm{A}=0 \mathrm{~g}, \mathrm{~B}=7 \mathrm{~g}, \mathrm{C}=14 \mathrm{~g}, \mathrm{D}=21 \mathrm{~g}$ and $\mathrm{E}=28 \mathrm{~g}$ of added sugar in $237 \mathrm{~mL}$ of chocolate milk

Panel of 190 assessors. 1: I dislike very much to 7: I like very much

Values followed by the same letter in the column do not differ significantly in the test at a 5\% significance level

Table 2: Acceptance for chocolate milk formulation

In the inner map of preference for aroma, the first and second principal components account for near range of values, together totalizing $60.54 \%$ (Figure 1). The aroma for samples C, E, D was further assessed, and compared to judges PC1 values of the samples B and A.

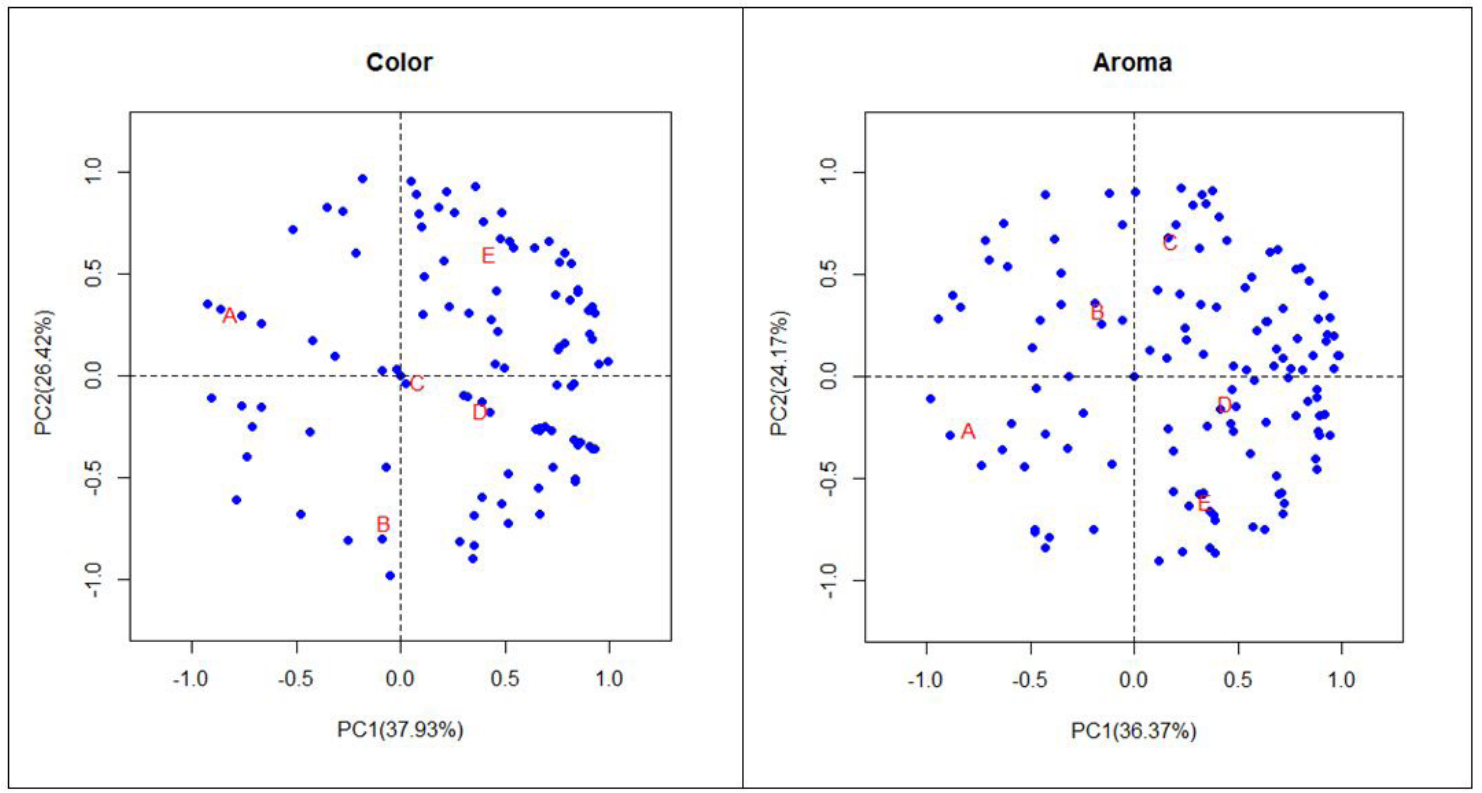

Figure 1: Internal preference map for the five chocolate samples in relation to: (a) color; and (b) aroma

In relation to the internal map of preference for the flavor of the chocolate samples, the two components explained $79.38 \%$ of the variation that exists among samples, and the first principal component explains $67.76 \%$ of the variation (Figure 2 ).

Samples D and E had the most popular taste among the judges, which did not occur with samples B, C and A.

Regarding texture, the first principal component (PC1) explains $51.59 \%$ of the total variation of $70.2 \%$ that exists between samples (Figure 3).

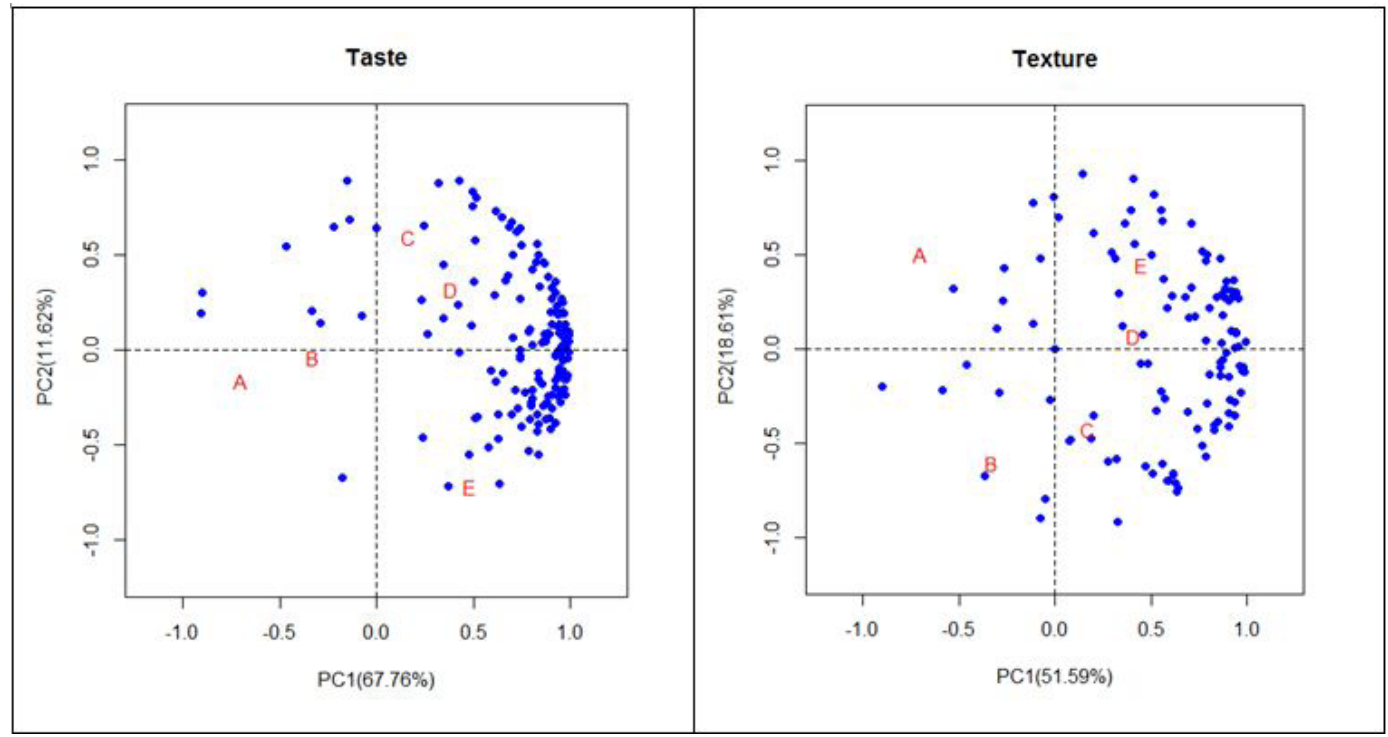

Figure 2: Internal map of preference for five chocolate samples in relation to: (a) taste; and (b) texture 
Again, samples C, D and E had the highest scores for texture, since samples A and B had the smallest notes, where 1 remained virtually isolated from the rest of the samples.

Regarding the overall acceptance of the chocolate samples, the preference map explains $78.48 \%$ of the total variation related to this attribute, being $64.86 \%$ of the total variation explained by the first principal component (PC1) and $13,62 \%$ by the second (PC2) (Figure 3). Samples E, D and C were the most preferred and samples A and B, the least preferred.

\section{Overall acceptance}

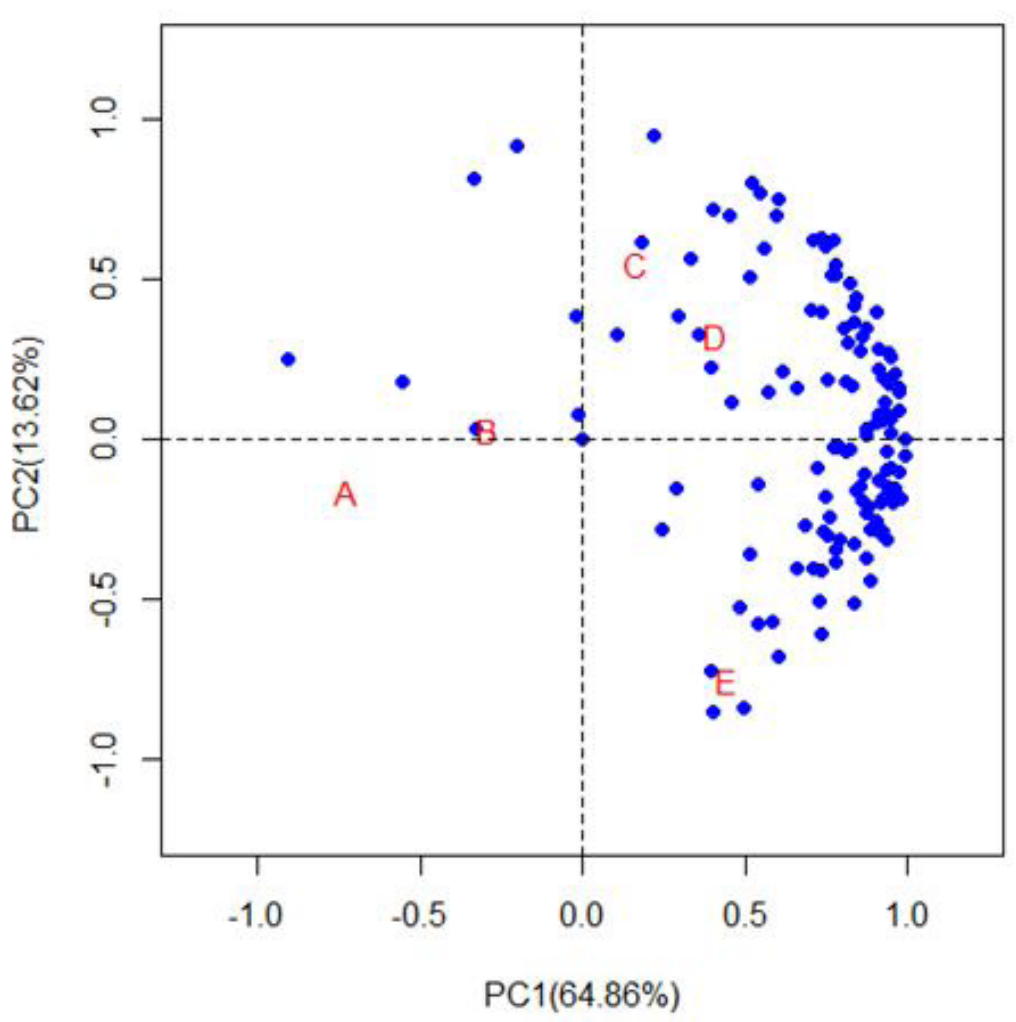

Figure 3: Internal map of preference for five chocolate samples in relation to the overall acceptance

For the attributes color and aroma, the sample without sugar was the least accepted; nonetheless, on a 7-point scale, there were more than 4 notes. For attributes flavor and texture, samples D and E were the most accepted and sample C showed notes 4.3 to 4.5 for flavor and texture, standing on the same scale as samples D and E. Considering a 7-point scale, it can be stated that there was no rejection of sample $\mathrm{C}$, indicating that the concentration of $14 \mathrm{~g}$ was also satisfactory. According to Cândido and Campos [16], sucrose helps giving texture to food, justifying the increased acceptance of the judges for texture.

\section{Conclusion}

The influence of flavor and texture was also checked in the global acceptance of the samples. From the sensory profile and evaluation of consumer acceptance, we identified important attributes, such as flavor and texture, which directed the preference of the judges, who accepted the milk with lower amounts of sugar. The data showed that the samples containing the highest concentrations of added sugar were more preferred than those with lower sugar levels.

\section{Acknowledgments}

We are grateful for a fellowship from the National Council of Technological and Scientific Development. Process numbers: 128273/2013-5 and 154615/2013-7.

\section{References}

1. McGuire S (2011) United States Department of Agriculture and U.S. Department of Health and Human Services Dietary Guidelines for Americans (2010) (7 ${ }^{\text {th }}$ Edn) Washington, DC: U.S Government Printing Office 2: 293-4.

2. Eduardo MF, Lannes SCS (2004) Chocolate drink powders: chemical analysis [Achocolatados: análise química]. Braz J Pharm Sci São Paulo 40: 405-12.

3. Murphy MM, Douglass JS, Johnson RK, Spence LA (2008) Drinking flavored or plain milk is positively associated with nutrient intake and is not associated with adverse effects on weight status in US children and adolescents. J Am Diet Assoc New York 108: 631-9. 
4. Li XE, Lopetcharat K, Qiu Y, Drake MA (2015) Sugar reduction of skim chocolate milk and viability of alternative sweetening through lactose hydrolysis. J Dairy Sci Champaign 98: 1455-66.

5. Meilgaard M, Civille GV, Carr BT (1999) Sensory evaluation techniques ( $3^{\text {rd }}$ Edn) CRC Press, Boca Raton, USA.

6. Rodrigue N, Guillet M, Fortin J, Martin JF (2000) Comparing information obtained from ranking and descriptive tests of four sweet corn products. Food Qual Prefer 11: 47-54

7. Richter VB, Avancini TC, Prudencio SH, Benassi MT (2010) Proposing a ranking descriptive sensory method. Food Qual Prefer 21: 611-20.

8. International Organization for Standardization (2006) ISO 8587: Sensory Analysis-Methodology Ranking, Geneva, Switzerland.

9. Carnelocce L, Seibel NF, Prudencio SH, Benassi MT (2012) Ranking Descriptive Analysis: application in the sensory characterization of cracker biscuits [Análise descritiva por ordenação: aplicação na caracterização sensorial de biscoitos laminados salgadosz]. Braz J Food Technol 15: 10.1590/S1981-67232012005000022.

10. Chaves JBP, Sproesser RL (1999) Laboratory practices of sensory analysis of food and beverages [Práticas de laboratório de analise sensorial de alimentos e bebidas], UFV, Viçosa, Brazil.

11. Moskowitz HR (1988) Applied sensory analysis of foods. CRC Press, Boca Raton, USA.

12. Macfie HJN, Bratchell N, Greenhoff K, Vallis L (1989) Designs to balance the effect of order of presentation and first-order carry-over effects in hall tests. J Sens Stud Bethesda 4: 129-48.

13. Newell GJ, MacFarlane JD (1987) Expanded tables for multiple comparison procedures in the analysis of ranked data. J Food Sci Champaign 52: 1721-5. 14. The R Foundation (2013) R Core Team R: A language and environment for statistical computing, R Foundation for Statistical Computing, Vienna, Austria. 15. Pflanzer SB, Cruz AG, Hatanaka CL, Mamede PL, Cadena R, et al. (2010) Sensory profile and acceptance of milk chocolate beverage [Perfil sensorial e aceitação de bebida láctea achocolatada]. Ciênc Tecnol Aliment Campinas 30: 10.1590/S0101-20612010000200016.

16. Candido LMB, Campos AM (1996) Alimentos para fins especiais: dietéticos. Livraria Varela São Paulo, Brazil.

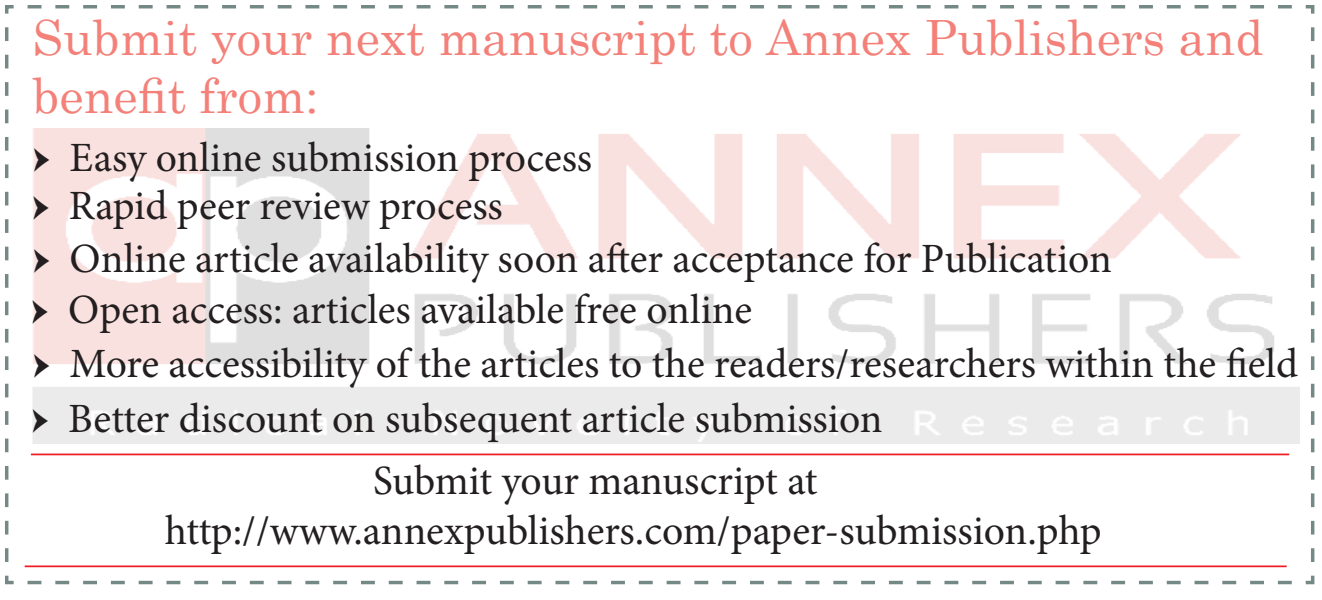

